\title{
Expiratory flow limitation during exercise in COPD: detection by manual compression of the abdominal wall
}

\author{
S. Abdel Kafi*, T. Sersté*, D. Leduc ${ }^{\#}$, R. Sergysels*, V. Ninane*
}

Expiratory flow limitation during exercise in COPD: detection by manual compression of the abdominal wall. S. Abdel Kafi, T. Sersté, D. Leduc, R. Sergysels, V. Ninane. (C) ERS Journals Ltd 2002.

ABSTRACT: Manual compression of the abdomen (MCA) during spontaneous expiration is a simple method for the detection of flow limitation in the chronic obstructive pulmonary disease (COPD) patients during resting breathing, based on comparison of flow/volume curves obtained during MCA with that of the preceding control breath. It was assessed whether this nonstandardized technique is also feasible during exercise.

MCA was performed during resting breathing and constant-exercise work at oneand two-thirds maximal mechanical power output $\left(W^{\prime} \max \right)$ in six normal subjects and 12 COPD patients. Changes in end-expiratory lung volume (EELV) were also studied.

With the aid of inspection, abdominal palpation and lung auscultation, MCA could always be applied during expiration. Flow limitation was never detected in the six normal subjects, whereas four of the COPD patients were flow limited at rest, seven during exercise at one-third $W^{\prime} \max$ and nine during exercise at two-thirds $W^{\prime} \max$. Expiratory flow limitation detected by MCA was always associated with an increase in EELV during exercise, indicating dynamic hyperinflation occurrence or increase.

It is concluded that manual compression of the abdomen is a very simple and reliable method for the detection of flow limitation during exercise.

Eur Respir J 2002; 19: 919-927.
*Chest and "Intensive Care Services, Saint-Pierre University Hospital, Brussels, Belgium.

Correspondence: V. Ninane, Chest Service, Saint-Pierre University Hospital, Rue Haute, 322, 1000 Brussels, Belgium.

Fax: 3225354174

E-mail: Vincent_NINANE@

stpierre-bru.be

Keywords: Chronic obstructive pulmonary disease, dynamic hyperinflation, exercise

Received: January 182001

Accepted after revision December 17 2001

D. Leduc was supported by a Fellowship Grant from the Vésale Foundation, Brussels, Belgium.
Dynamic pulmonary hyperinflation (DH) frequently occurs in chronic obstructive pulmonary disease (COPD) patients, both during acute conditions, such as respiratory failure [1,2], or exercise [3] and during resting breathing in the stable condition $[4,5]$. DH is associated with increased work of breathing at a time when the efficiency of the inspiratory muscles is decreased [6]. This condition can be revealed by detection of the so-called "intrinsic" positive end-expiratory pressure (PEEPi) that corresponds to the elastic recoil of the system at endexpiration [2]. In COPD patients with spontaneous breathing efforts, however, PEEPi is seldom measured, particularly because it ideally requires the positioning of oesophageal and gastric balloons [7, 8]. Since DH in COPD is mainly related to expiratory flow limitation, attention has turned towards simple tests that may allow recognition of expiratory flow limitation.

Expiratory flow limitation means that, despite increases in the driving pressures, expiratory flow cannot increase and tests, therefore, compare expiratory flow during spontaneous breathing with forced expiratory flow/volume curves. A very simple method for the detection of flow limitation based on manual compression of the abdomen (MCA) during spontaneous expiration and comparison of the generated expiratory flow with that of the preceding control breath has recently been proposed [9]. The advantages of this method relate to the fact that it does not require special devices or collaboration of the patient and can be performed in any position. In addition, changes in the antecedent volume and time history that may give false-positive results [10] do not occur and there is also no limitation related to increased upper airway collapsibility [9]. In contrast, a method which increases the alveolar airway opening pressure difference by negative pressures at the airway opening during spontaneous expiration using a special device (negative expiratory pressure (NEP)) [11-14] may occasionally cause upper airway collapse and, therefore, lead to a false-positive comparison $[9,15,16]$.

The time at which MCA is applied, however, cannot be chosen precisely and it was wondered whether this method, which is reliable in COPD patients breathing at rest [9], is still feasible in conditions such as exercise associated with increased breathing frequency and postural motions. Also, the pressure applied by the investigator is not precisely determined and, in some cases, causes pleural pressure increases of $>10 \mathrm{cmH}_{2} \mathrm{O}$ [9]. It may, therefore, be hypothesized that sufficient gas compression may occasionally occur, such that the registered expired lung volume significantly lags lung volume, leading to a false-positive comparison [17].

In the present study, the feasibility of MCA during exercise in normal subjects and COPD patients was 
assessed. It was reasoned that, if the MCA test is reliable during exercise, flow limitation should never be detected in normal subjects and, when detected in COPD patients with increasing levels of exercise, should always be associated with DH occurrence or increase. With this in mind, changes in end-expiratory lung volume (EELV) during exercise were also assessed. The results of the MCA tests were compared with the results of a method based on comparison of resting and forced vital capacity flow/volume loops $[18,19]$, referred to as the "conventional method".

\section{Material and methods}

\section{Subjects}

Six normal subjects and 12 COPD patients were studied (table 1). The six normal subjects (four males, two females; subjects 1-6) had a mean age of $28 \pm 4$ yrs, were recruited from hospital personnel and were aware of the purpose of the study. Their spirograms were within normal limits and none had any history of cardiopulmonary or neuromuscular disease. The 12 COPD patients (five males, seven females; subjects 7-18) had a mean age of $58 \pm 8$ yrs. They had a well-defined history of chronic airflow obstruction, and concomitant renal, hepatic, cardiovascular or neuromuscular disease was an exclusion criterion. None had a history of asthma. They were all smokers or exsmokers and had been in a medically stable condition for $\geqslant 4$ weeks when evaluated. Their main anthropometric data and lung volumes are given in table 1. Forced expiratory volume in one second
(FEV1) ranged $33-77 \%$ of the predicted value and FEV $1 /$ vital capacity ranged $39-67 \%$. All subjects gave informed consent to the procedures, as approved by the Human Studies Committee of Saint-Pierre University Hospital.

\section{Manual compression of the abdomen manoeuvre}

As previously described [9], the investigator put one hand gently on the abdominal wall of the subject with the palm at the level of the umbilicus, perpendicular to the axis between the xiphoid process and the pubis. The other hand was applied on the lower back of the patient in the same axis. In order to identify the expiratory phase during exercise breathing, inspection of the thorax and gentle palpation of the abdomen during repeated breathing cycles was used as well as lung auscultation as requested. The investigator informed the subject of the imminence of the MCA. Then, at the onset of expiration, a firm compression was exerted in the anteroposterior direction and maintained throughout the expiratory phase, and afterwards the hand was removed. MCA was always performed with the subject on the bicycle, in the same position, and the flow/volume loop during the MCA compared with the preceding "control" flow/volume loop [9].

\section{Procedure and measurements}

All subjects were studied on two consecutive days. On the first day, they had to perform an incremental symptom-limited bicycle exercise test. The subjects,

Table 1.-Anthropometric and functional characteristics and maximal exercise results of normal subjects and chronic obstructive pulmonary disease (COPD) patients

\begin{tabular}{|c|c|c|c|c|c|c|c|c|c|c|c|}
\hline Subject no. & Sex & $\begin{array}{l}\text { Age } \\
\text { yrs }\end{array}$ & $\begin{array}{l}\text { Height } \\
\mathrm{cm}\end{array}$ & $\begin{array}{c}\text { Weight } \\
\text { kg }\end{array}$ & $\begin{array}{c}\mathrm{VC} \\
\% \text { pred }\end{array}$ & $\begin{array}{l}\text { FEV1 } \\
\% \text { pred }\end{array}$ & $\begin{array}{c}\text { FRC } \\
\% \text { pred }\end{array}$ & $\begin{array}{l}\text { TLC } \\
\% \text { pred }\end{array}$ & $\begin{array}{c}W^{\prime} \max \\
\mathrm{W}\end{array}$ & $\begin{array}{l}V^{\prime} \mathrm{O}_{2}, \max \\
\% \text { pred }\end{array}$ & $\begin{array}{l}V^{\prime} \text { E,max } \\
\% \text { pred }\end{array}$ \\
\hline \multicolumn{12}{|l|}{ Normal subjects } \\
\hline 1 & M & 24 & 174 & 56 & 95 & 105 & 112 & 100 & 198 & 83 & 57 \\
\hline 2 & M & 32 & 184 & 78 & 113 & 111 & 126 & 109 & 270 & 105 & 76 \\
\hline 3 & M & 30 & 182 & 68 & 101 & 107 & 104 & 97 & 231 & 98 & 76 \\
\hline 4 & M & 32 & 170 & 74 & 97 & 106 & 80 & 88 & 188 & 79 & 52 \\
\hline 5 & $\mathrm{~F}$ & 23 & 172 & 50 & 78 & 84 & 105 & 86 & 138 & 91 & 56 \\
\hline 6 & $\mathrm{~F}$ & 25 & 169 & 57 & 103 & 106 & 112 & 101 & 120 & 76 & 44 \\
\hline \multirow{2}{*}{\multicolumn{12}{|c|}{ COPD patients }} \\
\hline & & & & & & & & & & & \\
\hline 7 & M & 69 & 167 & 59 & 58 & 33 & 131 & 80 & 48 & 53 & 36 \\
\hline 8 & M & 69 & 172 & 76 & 73 & 53 & 96 & 92 & 67 & 73 & 52 \\
\hline 9 & $\mathrm{~F}$ & 58 & 167 & 56 & 103 & 49 & 103 & 102 & 69 & 86 & 69 \\
\hline 10 & M & 54 & 172 & 80 & 89 & 67 & 94 & 102 & 124 & 83 & 59 \\
\hline 11 & $\mathrm{~F}$ & 57 & 160 & 64 & 72 & 56 & 158 & 116 & 68 & 75 & 60 \\
\hline 12 & $\mathrm{~F}$ & 59 & 160 & 54 & 79 & 38 & 182 & 124 & 56 & 73 & 51 \\
\hline 13 & $\mathrm{~F}$ & 50 & 175 & 63 & 85 & 64 & 128 & 98 & 82 & 79 & 59 \\
\hline 14 & $\mathrm{~F}$ & 70 & 160 & 55 & 75 & 39 & 162 & 120 & 69 & 88 & 51 \\
\hline 15 & $\mathrm{~F}$ & 49 & 164 & 50 & 99 & 77 & 125 & 107 & 70 & 67 & 44 \\
\hline 16 & $\mathrm{M}$ & 48 & 167 & 60 & 79 & 68 & 112 & 95 & 124 & 72 & 50 \\
\hline 17 & $\mathrm{~F}$ & 61 & 158 & 63 & 63 & 41 & 166 & 115 & 41 & 70 & 53 \\
\hline 18 & $\mathrm{M}$ & 59 & 170 & 72 & 97 & 72 & 111 & 97 & 58 & 51 & 45 \\
\hline Mean \pm SD & & $58 \pm 8$ & $166 \pm 6$ & $62 \pm 9$ & $81 \pm 14$ & $55 \pm 15$ & $131 \pm 30$ & $104 \pm 13$ & $73 \pm 26$ & $73 \pm 12$ & $52 \pm 9$ \\
\hline
\end{tabular}

VC: vital capacity; FEV1: forced expiratory volume in one second; FRC: functional residual capacity; TLC: total lung capacity; $W^{\prime}$ max: maximal mechanical power output; $V^{\prime} \mathrm{O}_{2}$, max: maximal oxygen uptake; $V^{\prime} \mathrm{E}$, max: minute ventilation during maximal exercise; \% pred: percentage of the predicted value; M: male; F: female. 
wearing a noseclip and mouthpiece, had to cycle at a rate of $\sim 60$ revolutions per minute until their tolerance limit on an electromagnetically-braked cycle ergometer (Medifit 1000S; Medical Fitness Equipment, Maarn, the Netherlands) that was connected to an automated exercise system (Oxycon Pro; Jaeger-Mynhardt, Bunnik, the Netherlands). Measurements included work rate, oxygen uptake $\left(V^{\prime} \mathrm{O}_{2}\right)$, ventilation and cardiac frequency. The ergospirometrically predicted values were calculated according to WASSERMAN et al. [20].

The day after incremental exercise testing, constantwork exercise testing at one- and two-thirds of maximal mechanical power output $\left(W^{\prime} \max \right)$ was performed using the same equipment for each subject. Exercise testing was preceded by a 10-min period of resting breathing in the same position but without cycling, so that the breathing pattern could stabilize. Maximal expiratory flow/volume curves were then performed after a rapid inspiration without end-inspiratory pause to ensure that there were no expiratory flow changes related to differences in the volume and time history of the preceding inspiration $[10,21]$. The measurements performed during stable resting breathing and after 5 min of exercise at one- and two-thirds $W^{\prime} \max$, at a time when $V^{\prime} \mathrm{O}_{2}$ and the breathing pattern were constant, included three inspiratory capacity and five MCA manoeuvres at each step. Great care was taken to avoid any change in EELV just before determining inspiratory capacity and $1 \mathrm{~min}$ of undisturbed breathing was allowed between each manoeuvre. The measurements at each step were completed within $7 \mathrm{~min}$, so that each period of exercise at one- and two-thirds $W^{\prime} \max$ lasted a maximum of $12 \mathrm{~min}$.

Using Oxycon Pro data analysis software, intrabreath analysis was initiated just before each control and test breath and stopped immediately thereafter. These flow/volume curves were superimposed on the maximal flow/volume curves at the highest inspiratory capacity [19]. With MCA, flow was considered limited whenever compression could not elicit an increase in expiratory flow during part of or throughout tidal expiration. In contrast, whenever MCA could elicit an increase in expiratory flow throughout tidal expiration, the subject was considered nonflow limited. With the conventional method, expiratory flow at comparable lung volumes that was similar to or even lower during forced vital capacity manoeuvres than during spontaneous expiration was indicative of flow limitation. EELV, end-inspiratory lung volume (EILV) and tidal volume were also assessed at each step.

When the $F$ ratio of the analysis of variance for repeated measures reached $<0.05$, modified t-tests (paired or unpaired, depending on the comparison being made) were used to compare inspiratory capacity, EELV and EILV, and tidal volume [22]. In the COPD patients, the Kruskal-Wallis test was used to assess the relationship between the results of MCA and functional characteristics as well as maximal exercise results. Data are presented as mean \pm SD.

\section{Results}

Effect of manual compression of the abdomen in normal subjects and chronic obstructive pulmonary disease patients

During exercise, thoracic inspection and abdominal palpation usually permitted identification of the expiratory phase, and lung auscultation was only required in two cases in order to perform MCA during spontaneous expiration. Figure 1 shows the effects of MCA in a normal subject (subject no. 6) breathing at rest and during exercise at one- and two-thirds $W^{\prime} \max$. Relative to the preceding control breath, the MCA flow/volume curve always showed increased expiratory flow over the entire range of control tidal expiration. Similar findings were obtained in the other normal subjects. In three of the 12 COPD patients, MCA was also associated with increased expiratory flow at each exercise level. In contrast, flow limitation was detected by MCA in the other nine patients.
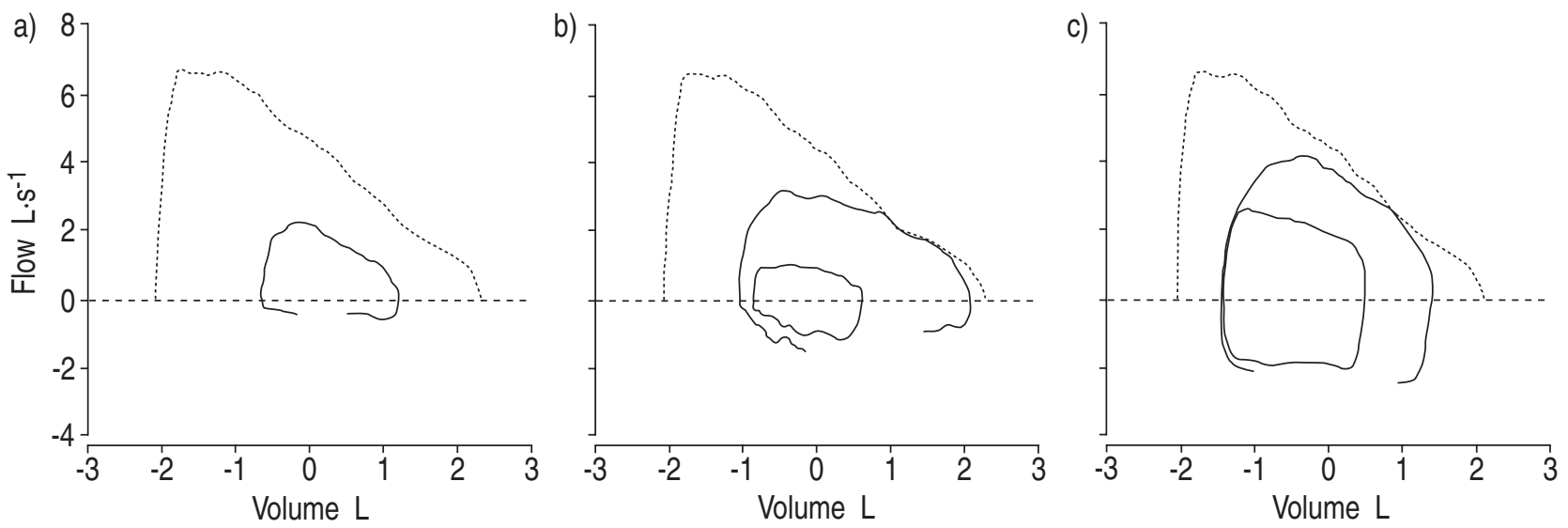

Fig. 1.- Superimposed flow/volume curves from manual compression of the abdomen (MCA) during expiration (open loop) and the preceding control breath (closed loop) in a normal subject (subject no. 6) at: a) rest; and during constant-work exercise at: b) one-third; and c) two-thirds of maximal mechanical power output. The maximal expiratory flow/volume curve measured at forced vital capacity is also shown (……....----: end-expiratory lung volume (EELV) measured during resting breathing on the bicycle. Note that MCA elicits increased expiratory flow relative to the control breath at each exercise level and that exercise is associated with decreased EELV. 

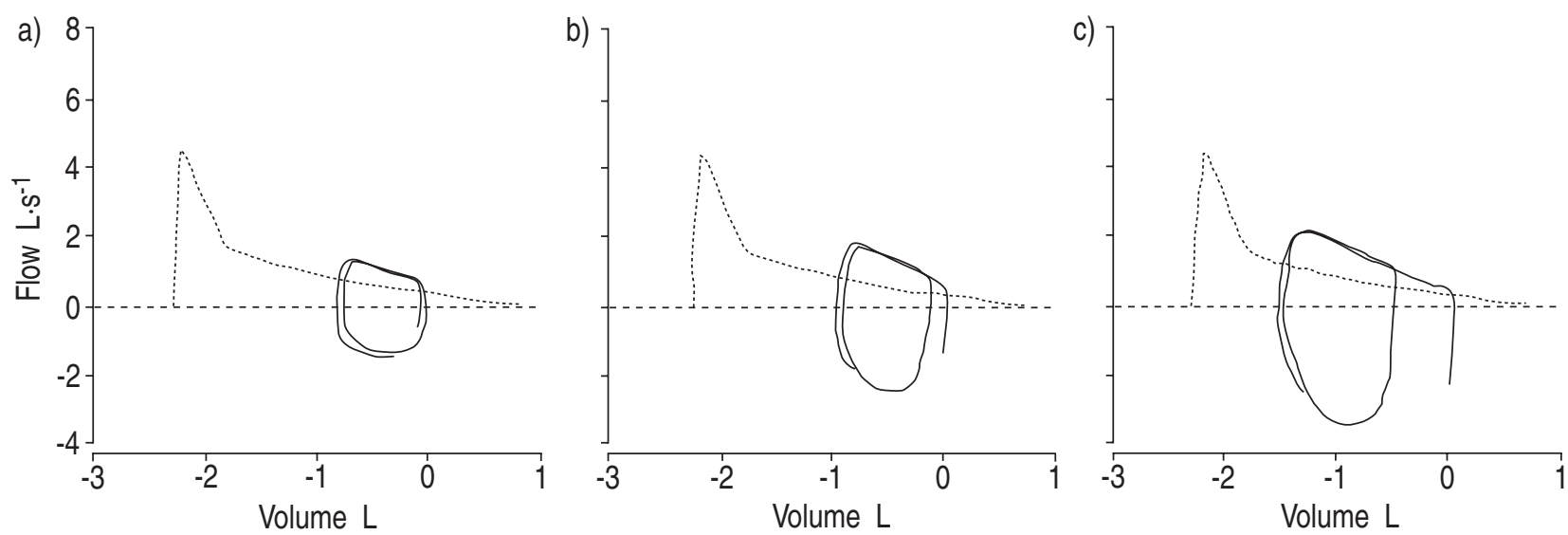

Fig. 2. - Superimposed flow/volume curves from manual compression of the abdomen (MCA) during expiration (open loop) and the preceding control breath (closed loop) in a chronic obstructive pulmonary disease patient (subject no. 12) at: a) rest; and during constantwork exercise at: b) one-third; and c) two-thirds of maximal mechanical power output. The maximal expiratory flow/volume curve measured at forced vital capacity is also shown (……...). ------: end-expiratory lung volume (EELV) measured during resting breathing on the bicycle. Note that MCA does not induce increased expiratory flow relative to the control breath at the three exercise levels and that exercise is associated with a progressive increase in EELV.

In four of them, as illustrated by a representative patient in figure 2, MCA indicated flow limitation during resting breathing and at both exercise levels. In two of the patients, as illustrated in figure 3, MCA indicated flow limitation only at the highest level of exercise. In the remaining three patients, as illustrated in figure 4, MCA indicated increased flow during resting breathing but not during exercise. In the present as well as previous studies [9], the flow/volume curve associated with the highest expiratory flow (during part of or throughout tidal expiration) always corresponded with the MCA manoeuvre rather than the control. In contrast, in flow limitation, expiratory flow was similar and the MCA and control curves were not significantly different.

Comparison between MCA and the conventional method showed similar results in the normal subjects: each of the forced expiratory manoeuvres always generated increased expiratory flow. In contrast, contradictory results were frequently present in the COPD patients during resting breathing or exercise (figs. 3 and 4, and table 2). Indeed, the conventional method led to false-positive results in five patients during resting breathing, four during exercise at one-third $W^{\prime} \max$ and two during exercise at twothirds $W^{\prime} \max$ since, in each of these cases, MCA generated increased expiratory flow (table 2). These contradictory results are particularly well illustrated by subject no. 10. In this particular patient (table 2), the conventional method showed false-positive results at each exercise level since MCA was always able to increase expiratory flow.

In some cases, in some subjects, MCA could not be applied at the very beginning of expiration but, even when somewhat delayed, always allowed consistent interpretation with repeated tests in each
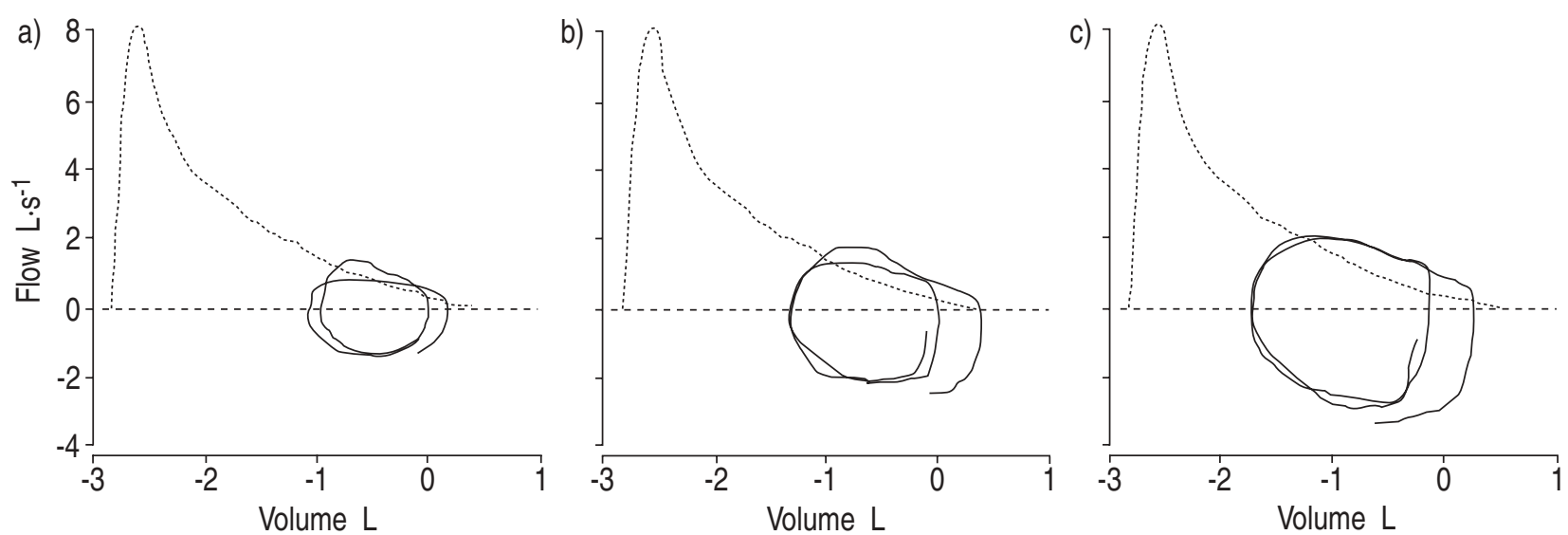

Fig. 3.-Superimposed flow/volume curves from manual compression of the abdomen (MCA) during expiration (open loop) and the preceding control breath (closed loop) in a chronic obstructive pulmonary disease patient (subject no. 13) at: a) rest; and during constantwork exercise at: b) one-third; and c) two-thirds of maximal mechanical power output ( $W^{\prime}$ max). The maximal expiratory flow volume curve measured at forced vital capacity is also shown (...........). ------: end-expiratory lung volume (EELV) measured during resting breathing on the bicycle. Note that MCA induces increased expiratory flow relative to the control breath during resting breathing and exercise at one-third $W^{\prime} \max$ but not during exercise at two-thirds $W^{\prime}$ max. The latter level is also associated with a clear-cut increase in EELV. Note also that flow at forced expiratory vital capacity is less than or equal to tidal expiratory flow at the three exercise levels. 

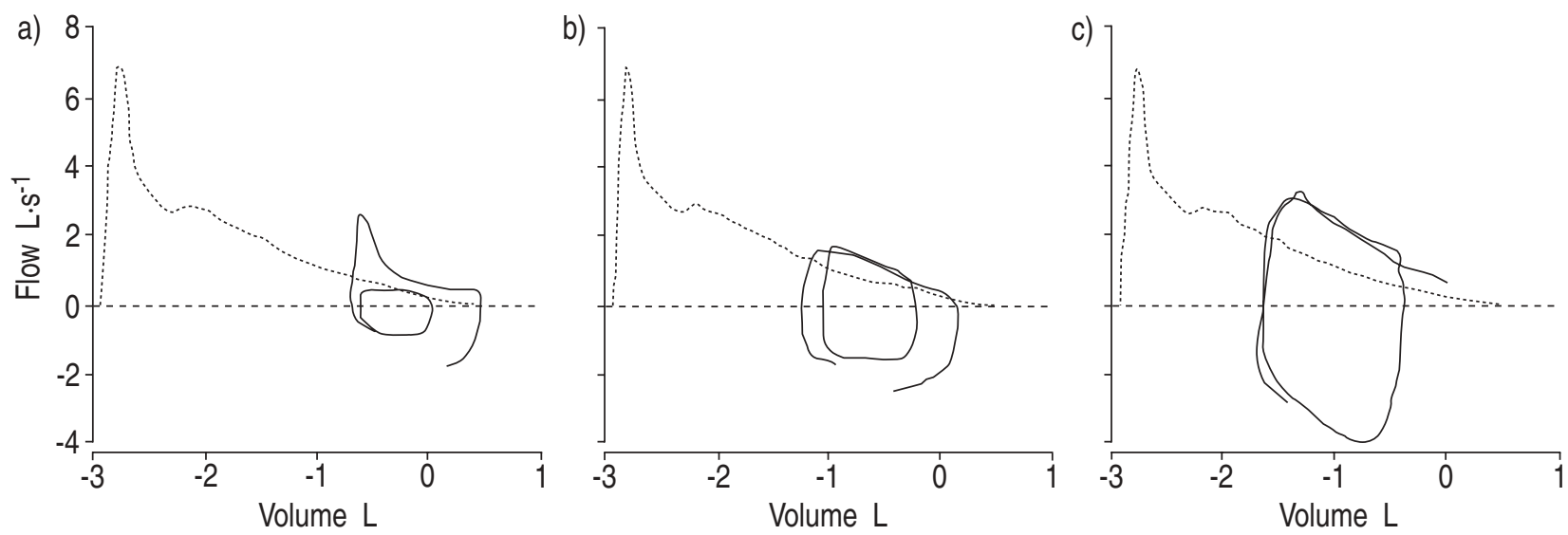

Fig. 4.-Superimposed flow/volume curves from manual compression of the abdomen (MCA) during expiration (open loop) and the preceding control breath (closed loop) in a chronic obstructive pulmonary disease patient (subject no. 9) at: a) rest; and during constantwork exercise at: b) one-third; and c) two-thirds of maximal mechanical power output. The maximal expiratory flow/volume curve measured at forced vital capacity is also shown $(\cdots \cdots \cdots . .$.$) . ------: end-expiratory lung volume (EELV) measured during resting breathing on$ the bicycle. Note that MCA induces increased expiratory flow relative to the control breath during resting breathing but not during exercise that is also associated with a clear-cut increase in EELV.

subject. The test was also well tolerated and none of the subjects reported pain during the manoeuvre. Reflex glottic closure was only observed in one patient and this closure was evident as a transient decrease in expiratory flow on the test flow/volume curve [9].

\section{Changes in end-expiratory lung volume and tidal volume with exercise}

As already well documented [13, 19, 23, 24], exercise was associated with significant changes in EELV $(p<0.05)$ in a way that differed between the two groups $(p<0.05)$ (fig. 5). Indeed, whereas, in the normal subjects the transition from resting breathing to one-third $W^{\prime} \max$ exercise was associated with a

Table 2. - Flow limitation detection in 12 chronic obstructive pulmonary disease patients using manual compression of the abdomen (MCA) or comparison of tidal and maximal expiratory flow/volume loops $\left(\max V^{\prime} / V\right)$

\begin{tabular}{|c|c|c|c|c|c|c|}
\hline \multirow{2}{*}{$\begin{array}{l}\text { Subject } \\
\text { No. }\end{array}$} & \multicolumn{2}{|c|}{ Resting breathing } & \multicolumn{2}{|c|}{$1 / 3 W^{\prime} \max$} & \multicolumn{2}{|c|}{$2 / 3 W^{\prime} \max$} \\
\hline & MCA & $\begin{array}{l}\max \\
V^{\prime} / V\end{array}$ & $\mathrm{MCA}$ & $\begin{array}{l}\max \\
V^{\prime} / V\end{array}$ & MCA & $\begin{array}{l}\max \\
V^{\prime} / V\end{array}$ \\
\hline 7 & $-*$ & + & + & + & + & + \\
\hline 8 & + & + & + & + & + & + \\
\hline 9 & $-*$ & + & + & + & + & + \\
\hline 10 & $-*$ & + & $-^{*}$ & + & -* & + \\
\hline 11 & + & + & + & + & + & + \\
\hline 12 & + & + & + & + & + & + \\
\hline 13 & $-*$ & + & $-^{*}$ & + & + & + \\
\hline 14 & $-*$ & + & + & + & + & + \\
\hline 15 & - & - & - & - & - & - \\
\hline 16 & - & - & $-*$ & + & $-*$ & + \\
\hline 17 & + & + & + & + & + & + \\
\hline 18 & - & - & $-*$ & + & + & + \\
\hline
\end{tabular}

*: contradicts conventional $\left(\max V^{\prime} / V\right)$ method. $W^{\prime} \max$ : maximal mechanical power output. +: flow limitation; -: no flow limitation. decrease in EELV $(\mathrm{p}<0.005)$, a significant EELV increase was observed in the COPD patients between one- and two-thirds $W^{\prime} \max$ exercise $(\mathrm{p}<0.05)$. Exercise was also associated with significant increases in EILV in both groups $(\mathrm{p}<0.001)$ (fig. 5).

Changes in EELV, with exercise as a function of the results of the MCA test, are illustrated by the individual data in figure 6. Whenever flow limitation was detected by MCA, it was associated with an increase in EELV. This is particularly well illustrated by the four patients who were flow limited from rest and clearly showed a progressive increase in EELV with exercise. These patients also tended to have the highest degree of lung hyperinflation at rest (fig. 6). In contrast, the three COPD patients who were never flow limited with MCA showed an initial decrease

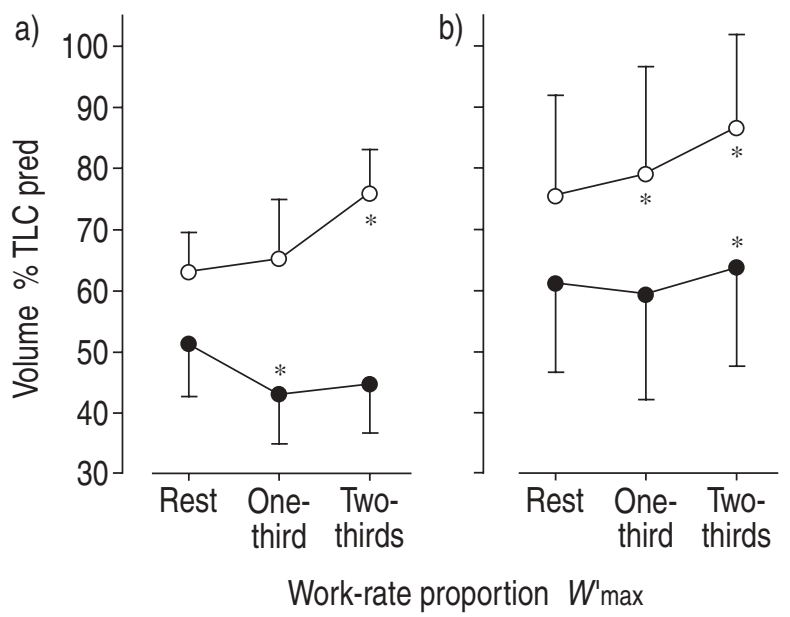

Fig. 5. - Changes in end-expiratory $(\bullet)$ and end-inspiratory $(\bigcirc)$ lung volumes from breathing at rest to exercise at one- and twothirds of maximal mechanical power output ( $\left.W^{\prime} \max \right)$ in: a) normal subjects; and b) chronic obstructive pulmonary disease patients. Data are presented as mean \pm SD. See Changes in end-expiratory lung volume and tidal volume with exercise section for further explanation. \% TLC pred: percentage of predicted total lung capacity. ${ }^{*}: \mathrm{p}<0.05$ versus previous value. 

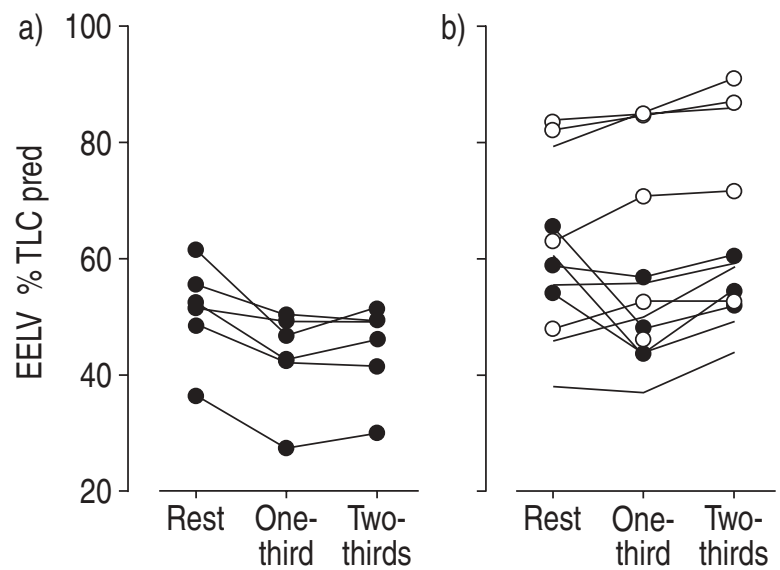

Work-rate proportion $W^{\prime} \max$

Fig. 6. - Changes in end-expiratory lung volume (EELV) from breathing at rest to exercise at one- and two-thirds of maximal mechanical power output $\left(W^{\prime} \max \right)$ in: a) six normal subjects; and b) 12 chronic obstructive pulmonary disease (COPD) patients. Note that EELV is clearly decreased during exercise at one-third $W^{\prime} \max$ in COPD patients who never show flow limitation using manual compression of the abdomen $(\bullet)$. In contrast, patients who are flow limited from rest $(\bigcirc)$ show a progressive increase in EELV with exercise and tend also to have higher EELVs during resting breathing. - : other patterns of flow limitation. \% TLC pred: percentage of predicted total lung capacity.

in EELV, as normal subjects did. In these patients, as well as in three normal subjects, increasing the exercise level up to two-thirds $W^{\prime} \max$ was associated with a small increase in EELV, which remained, however, in all but one of them, below the initial values measured during resting breathing.

Tidal volume increased with exercise in both the normal subjects and the COPD patients $(\mathrm{p}<0.001)$, but to a greater extent in the former $(p<0.05)$ (fig. 7). At two-thirds $W^{\prime} \max$, the tidal volume increase amounted to $156 \%$ in normal subjects but only $64 \%$ in COPD patients $(\mathrm{p}<0.05)$. More interestingly, in the COPD patients, tidal volume changes seemed to depend upon the results of the MCA test $(p<0.05)$. Indeed, the tidal volume increase was greater during exercise in patients who never showed flow limitation than in those flow limited from rest $(\mathrm{p}<0.05)$.

\section{Relationship between manual compression of the abdomen results, maximal exercise results and functional characteristics of chronic obstructive pulmonary disease patients}

Even if expiratory flow limitation was found to affect the ventilatory response to exercise (fig. 6), no difference was found in maximal exercise results ( $W^{\prime}$ max, maximal $V^{\prime} \mathrm{O}_{2}$ or minute ventilation, expressed as a percentage of the predicted value) between the COPD patients who were flow limited from rest, those who became flow limited during exercise and those who were never flow limited.

Similarly, the functional characteristics of these three groups of patients did not differ. For example, mean FEV1 tended to be lower in patients who were

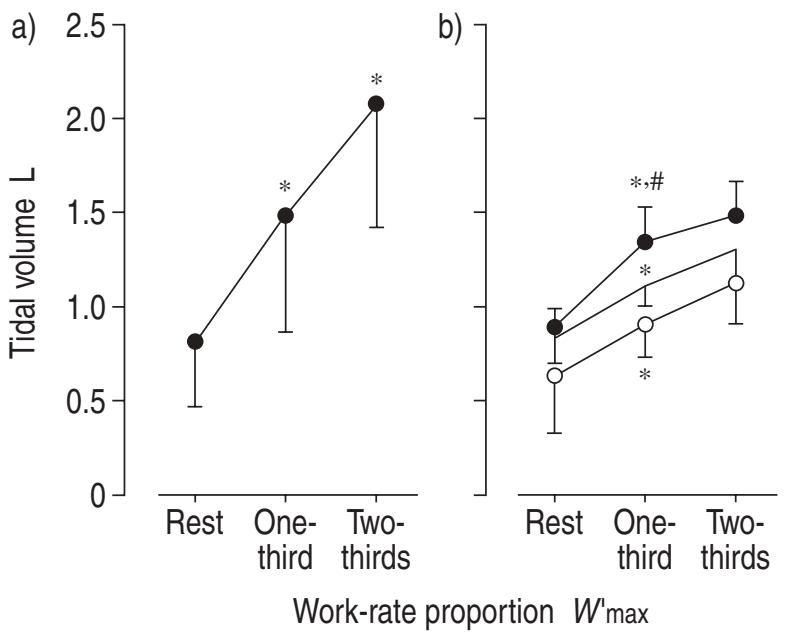

Fig. 7.-Changes in tidal volume from breathing at rest to exercise at one- and two-thirds of maximal mechanical power output $\left(W^{\prime} \max \right)$ in: a) normal subjects; and b) chronic obstructive pulmonary disease (COPD) patients according to manual compression of the abdomen (MCA) results ( $O$ : never flow limited; $\bigcirc$ : flow limited from rest; - : other patterns of flow limitation). Tidal volume increased with exercise in both groups but the increase was significantly greater in the normal subjects. The increase in tidal volume in the COPD group was dependent upon the results of MCA. See Changes in end-expiratory lung volume and tidal volume with exercise section for further explanation. *: $\mathrm{p}<0.05$ versus previous value; ${ }^{\#}: \mathrm{p}<0.05$ versus subjects flow limited from rest.

flow limited from rest $(47 \pm 9 \%$ pred) than in those who became flow limited during exercise breathing $(51 \pm 16 \%$ pred) or those who were never flow limited $(71 \pm 6 \%$ pred), although this relationship failed to reach the level of significance $(\mathrm{p}=0.09)$.

\section{Discussion}

The present studies have shown that, with the aid of inspection, abdominal palpation and, as a last resort, lung auscultation, MCA can be applied in normal subjects during spontaneous breaths and in COPD patients during exercise. In accordance with previous work [19, 23], MCA never detected flow limitation during exercise in the normal young subjects. In contrast, flow limitation was often detected with MCA in the COPD patients during resting breathing or at increasing levels of exercise. Limitation detected in this way was systematically associated with an increase in EELV during exercise. Finally, this test was well tolerated. The present studies thus demonstrate that the nonstandardized MCA test is easy to apply, even in conditions associated with increased breathing frequency and postural motion. This method is also reliable, since flow limitation detected in this way was systematically associated with DH occurrence or increase during exercise.

It has recently been shown that compression of the abdominal wall with one hand, by grossly mimicking the mechanical action of the abdominal muscles, invariably causes an increase in gastric and pleural pressures and thereby an increase in the pressure gradient between the alveolar and the airway opening 
[9]. During resting expiration, this manoeuvre always caused an increase in expiratory flow in normal subjects, whereas no expiratory flow increase was present in some COPD patients, including those with the most severe airway obstruction [9]. The present study during bicycle exercise in normal subjects and COPD patients not only extends the authors' previous findings, but also shows that inspection and abdominal palpation in this situation most often permitted identification of the expiratory phase and the appropriate time for compression of the abdomen. Inspection may also help to identify paradoxical abdominal motion during resting or exercise breathing. Whenever these methods failed, lung auscultation proved useful. In some cases, however, compression could not be applied at the very beginning of resting expiration during exercise. Since flow limitation can be present during the entire range or only the lower part of volume change during resting expiration and not the reverse [9-13], delayed compression did not affect test interpretation. Indeed, in the present study, patients were considered flow limited whether flow limitation was present during the entire range or restricted to the lower part of volume change during resting expiration.

Limitations related to tonic contraction of the diaphragm and abdominal muscles during exercise

During exercise or limb movement, the diaphragm and transversus abdominis are also involved in postural tasks $[25,26]$. It may therefore be hypothesized that tonic activity of the diaphragm, for example, may affect the results of MCA through intra-abdominal pressure increases. This possible limitation, however, is unlikely to be important because the MCA test is qualitative. It is also highly unlikely that the lack of increase in expiratory flow during MCA in COPD patients with increasing levels of exercise is related to tonic contraction of the diaphragm and/or abdominal muscles for the following reasons. First, this limitation should also apply to the six normal subjects studied, such that "false" expiratory flow limitation should also have been observed in them. However, MCA always caused a clear-cut increase in expiratory flow with increasing exercise levels in normal subjects. Secondly, in the condition of increased intra-abdominal pressure associated with tonic postural contraction of the transversus abdominis and diaphragm, respiratory airflow is achieved by cyclic changes in the shape of the pressurized abdominal cavity due to alternate modulation of ongoing transversus abdominis and diaphragmatic contraction $[25,26]$. With this in mind, MCA may be considered as a means of amplifying expiratory modulation by mimicking the mechanical action of the transversus abdominis. Thirdly and finally, whenever flow limitation was detected with MCA, it was associated with EELV increase. This relationship would not have been systematically present in the case of false expiratory flow limitation related to tonic postural contraction of respiratory muscles.
False-positive comparisons related to gas compression during manual compression of the abdomen

Several observations suggest that the gas compression artefact [17] does not play a significant role during flow limitation assessment with MCA. First, the compression force was not calibrated and it would be expected, if this limitation was present in the manoeuvres associated with the highest intrathoracic pressures, that this method might lead to conflicting results in any given subject. In contrast, analysis of successive MCA tests led to consistent interpretation in any given subject. Secondly, the finding that flow limitation detected by MCA was systematically associated with increases in EELV (fig. 6) also argues against the hypothesis of false-positive comparison related to gas compression. Finally, MCA could still increase expiratory flow in 11 situations, in seven patients, in which flow limitation was suspected on the basis of the conventional method (table 2). However, on the basis of MCA results, the conventional method, which is clearly associated with possible gas compression artefact [17], led to $35 \%$ false-positive comparisons.

As illustrated in table 2, contradictory results between MCA and the conventional method were observed in only two (subjects no. 10 and 16) of the twelve COPD patients during exercise at two-thirds $W^{\prime} \max$. However, with increasing ventilation, the prevalence of "true" expiratory flow limitation increases, which should reduce the disagreement between the two methods. This is particularly well illustrated by the group of five patients showing contradictory results at rest: disagreement between the two methods was present in only one of them during exercise at two-thirds $W^{\prime} \max$ (subject no. 10). At the same time, however, disagreement may potentially increase with increasing (exercise) ventilation, because, in patients who are not flow limited at rest on the basis of both assessments, overestimation with the conventional method may appear during exercise, as illustrated by subjects no. 16 and 18 . This is probably due to the fact that, with the latter method, artefacts related to gas compression and changes in time and volume history [9, 17], in a patient whose ventilation gets progressively closer to limitation, may become significant and lead to false-positive comparison.

In the present study, flow limitation on the basis of the MCA test was always associated with increases in EELV. In contrast, increases in EELV were occasionally observed during increasing exercise in the absence of flow limitation, presumably as a consequence of decreased expiratory time and increased tidal volume. As previously reported [13, 23, 27], in the group of patients with COPD, the tidal volume increase during exercise was less than that in the control group. The pattern of change in tidal volume with exercise in the COPD patients also varied as a function of the MCA results: the increase was smaller in the COPD patients who were flow limited from rest than in those who never showed flow limitation on MCA (fig. 7). The smaller increase in tidal volume in the patients limited from rest is probably due to severe DH during exercise (fig. 6) together with increased 
elastic work of breathing and decreased efficiency of the inspiratory muscles $[2,6]$. As in a previous study [13], the authors of the present study found no significant relationship between the results of flow limitation detection and maximum exercise capacity. This may be explained by the small number of patients studied and by variability in other factors contributing to exercise performance, such as physical deconditioning. Indeed, in a recent larger study (52 patients), the results of flow limitation detection using the NEP technique were related to maximal exercise data [28].

The NEP technique has recently been shown to be a reliable method for the detection of flow limitation during resting breathing and during exercise [12, 13]. Relative to MCA, this method has the advantage that the pressure applied and the time when it is applied are chosen, but it requires a special device and, in contrast to MCA, the results may occasionally be affected by increased upper airway collapsibility $[9,15]$. According to the facilities available, one of these two techniques or their combination may be used to detect flow limitation in the COPD patient breathing at rest or during exercise.

Detection of expiratory flow limitation during exercise in COPD may have clinical implications. Expiratory flow limitation is the main factor contributing to the development of $\mathrm{DH}$ in the COPD patient and conditions during incremental exercise or even daily activities have been shown to be major contributors to breathlessness [14, 27, 29]. The simple MCA test, which does not require the cooperation of the patient, may be of help in better understanding the mechanisms of exercise-associated dyspnoea in COPD patients. In addition, detection of flow limitation may be of interest since it affects the ventilatory response to exercise (fig. 6), as well as maximum exercise capacity [28].

In conclusion, compression of the abdominal wall with one hand is a very simple and reliable test that allows flow limitation detection during resting breathing as well as during exercise. This method requires no special device nor cooperation of the patient.

\section{References}

1. Pepe PE, Marini JJ. Occult positive end-expiratory pressure in mechanically ventilated patients with airflow obstruction. Am Rev Respir Dis 1982; 126: 166170.

2. Rossi A, Polese G, Brandi G, Conti G. Intrinsic positive end-expiratory pressure (PEEPi). Intensive Care Med 1995; 21: 522-536.

3. Potter WA, Olafsson S, Hyatt RE. Ventilatory mechanics and expiratory flow limitation during exercise in patients with obstructive lung disease. J Clin Invest 1971; 50: 910-919.

4. Haluszka J, Chartrand DA, Grassino AE, Milic-Emili J. Intrinsic PEEP and arterial $\mathrm{PCO}_{2}$ in stable patients with chronic obstructive pulmonary disease. Am Rev Respir Dis 1990; 141: 1194-1197.

5. Dal Vecchio L, Polese G, Poggi R, Rossi A. "Intrinsic" positive end-expiratory pressure in stable patients with chronic obstructive pulmonary disease. Eur Respir $J$ 1990; 3: 74-80.
6. Tzelepis G, McCool FD, Leith DE, Hoppin FG. Increased lung volume limits endurance of inspiratory muscles. J Appl Physiol 1988; 64: 1796-1802.

7. Ninane V. "Intrinsic" PEEP (PEEPi): role of expiratory muscles. Eur Respir J 1997; 10: 516-518.

8. Younes M. Dynamic intrinsic PEEP (PEEP(i),dyn): is it worth saving? Am J Respir Crit Care Med 2000; 162: $1608-1609$

9. Ninane V, Leduc D, Abdel Kafi S, Nasser M, Houa M, Sergysels R. Detection of expiratory flow limitation by manual compression of the abdominal wall. Am J Respir Crit Care Med 2001; 163: 13261330.

10. Milic-Emili J, Koulouris NG, D'Angelo E. Spirometry and flow-volume loops. Eur Respir Mon 1999; 12: $20-32$.

11. Valta P, Corbeil C, Lavoie A, et al. Detection of expiratory flow limitation during mechanical ventilation. Am J Respir Crit Care Med 1994; 150: 13111317.

12. Koulouris NG, Valta $\mathrm{P}$, Lavoie A, et al. A simple method to detect expiratory flow limitation during spontaneous breathing. Eur Respir J 1995; 8: 306313.

13. Koulouris NG, Dimopoulou I, Valta P, Finkelstein $\mathrm{R}$, Cosio MG, Milic-Emili J. Detection of expiratory flow limitation during exercise in COPD patients. J Appl Physiol 1997; 82: 723-731.

14. Eltayara L, Becklade MR, Volta CA, Milic-Emili J. Relationship of chronic dyspnea and flow limitation in COPD patients. Am J Respir Crit Care Med 1996; 154: $1726-1734$.

15. Liistro G, Veriter C, Dury M, Aubert G, Stanescu D. Expiratory flow limitation in awake sleep-disordered breathing subjects. Eur Respir J 1999; 14: 185-190.

16. Tantucci C, Duguet A, Ferretti A, et al. Effect of negative expiratory pressure on respiratory system flow resistance in awake snorers and nonsnorers. J Appl Physiol 1999; 87: 969-976.

17. Ingram RH, Schilder DP. Effect of gas compression on pulmonary pressure, flow and volume relationship. J Appl Physiol 1966; 21: 1821-1826.

18. Hyatt RE. The interrelationship of pressure, flow and volume during various respiratory maneuvers in normal and emphysematous patients. Am Rev Respir Dis 1961; 83: 676-683.

19. Johnson BD, Weisman IM, Zeballos RJ, Beck KC. Emerging concepts in the evaluation of ventilatory limitation during exercise. The exercise tidal flowvolume loop. Chest 1999; 116: 488-503.

20. Wasserman K, Hansen JE, Sue DY, Whipp BJ, Casaburi R, Principles of Exercise Testing and Interpretation. 2nd Edn. Philadelphia, PA, Lea \& Febiger, 1994.

21. D'Angelo E, Prandi E, Marrazzini L, Milic-Emili J. Dependence of maximal flow-volume curves on time course of preceding inspiration in patients with chronic obstructive lung disease. Am J Respir Crit Care Med 1994; 150: 1581-1586.

22. Winer BJ, Statistical Principles in Experimental Design. 2nd Edn. New York, NY, McGraw-Hill, 1971.

23. Beck KC, Staats BA, Hyatt RE, Babb TG. Dynamics of breathing during exercise. In: Whipp BJ, Wasserman K, eds. Exercise. New York, NY, Dekker, 1991; pp. 67-97.

24. Gallagher CG. Exercise limitation and clinical exercise 
testing in chronic obstructive pulmonary disease. Clin Chest Med 1994; 15: 305-326.

25. Hodges PW, Gandevia SC. Changes in intra-abdominal pressure during postural and respiratory activation of the human diaphragm. J Appl Physiol 2000; 89: 967976.

26. Hodges PW, Gandevia SC, Richardson CA. Contractions of specific abdominal muscles in postural tasks are affected by respiratory maneuvers. J Appl Physiol 1997; 83: 753-760.

27. O'Donnell DE, Webb KW. Exertional breathlessness in patients with chronic airflow limitation. The role of lung hyperinflation. Am Rev Respir Dis 1993; 148: 1351-1357.

28. Diaz O, Villafranca C, Ghezzo H, et al. Role of inspiratory capacity on exercise tolerance in COPD patients with and without tidal expiratory flow limitation at rest. Eur Respir J 2000; 16: 269-275.

29. Marin JM, Carrizo SJ, Gascon M, Sanchez A, Gallego B, Celli BR. Inspiratory capacity, dynamic hyperinflation, breathlessness, and exercise performance during the 6-minute-walk test in chronic obstructive pulmonary disease. Am J Respir Crit Care Med 2001; 163: 1395-1399. 